\title{
A Case of Severe Amitriptyline Intoxication: Electrocardiography Signs Suggesting Ventricular Tachycardia \\ $\mathrm{H}_{\text {Keskin }}{ }^{1}$, F Laloğlu ${ }^{2}$, MO Yalçınöz ${ }^{3}, \mathrm{M} \mathrm{Kara}^{4}, \mathrm{H} \mathrm{Olgun}^{2}, \mathrm{~N} \mathrm{Ceviz}^{2}$
}

\begin{abstract}
Amitriptyline poisoning may result in severe neurological and cardiac problems. We report a case of (13-month girl) severe amitriptyline intoxication with neurological, respiratory and electrocardiographic findings. With respiratory support, seizure control, $\mathrm{NaHCO}_{3}$ infusion, intravenous lipid infusion, selective plasma exchange and arrhythmia control the patient recovered. We stressed that amitriptyline intoxication may lead to severe problems. Electrocardiographic findings may not be differentiated from ventricular tachycardia. In these patients, survey may be well with aggressive treatment modalities.
\end{abstract}

Keywords: Aggressive treatment, amitriptyline, intoxication, ventricular tachycardia

From: ${ }^{1}$ Department of Pediatric Intensive Care Unit, Atatürk University School of Medicine, Erzurum, Turkey, ${ }^{2}$ Department of Pediatric Cardiology, Atatürk University School of Medicine, Erzurum, Turkey, ${ }^{3}$ Department of Pediatrics, Atatürk University School of Medicine, Erzurum, Turkey ${ }^{4}$ Department of Neonatology, Atatürk University School of Medicine, Erzurum, Turkey.

Correspondence: Professor N Ceviz, Division of Pediatric Cardiology, School of Medicine Atatürk University, 2500, Erzurum, Turkey. E-mail: ceviznaci@yahoo.com 


\section{INTRODUCTION}

Amitriptyline is one of the most commonly used tricyclic antidepressants. Clinical results of amitriptyline poisoning are well defined in adults and in children (1-4). Amitriptilin poisoning may result in severe neurological and cardiac problems. Treatment may be challenging and even death may occur (5). In this paper we aimed to report a child with severe amitriptyline poisoning and discuss the urgent treatment options.

\section{CASE REPORT}

A 13-month old girl was admitted to emergency department of the local state hospital with the suspicion of drug intake (Laroxyl ${ }^{\circledR} 10 \mathrm{mg}$ drage, containing amitriptyline) 2 hours previous to the admission. The amount of the possibly ingested drug was not known. The patient had been admitted after recognition of the newly developed somnolance. Physical findings had revealed unconsciousness, flexor response to painfull stimuli and bilateral negative pupillary light reflex. After gastric lavage, active choarchal had been administered. Complete blood count, liver and renal functions and serum electrolytes had found to be normal. Blood gase analysis had found as following; $\mathrm{pH}=7.24, \mathrm{pCO}_{2}=54 \mathrm{mmHg}, \quad \mathrm{HCO}_{3}=19.4 \mathrm{mmol} / \mathrm{L}$, Lac $=2.7 \mathrm{mmol} / \mathrm{L}$. During monitorization ventricular tachycardia (VT) (Figure- 1 and Figure2) had been detected and lidocain infusion had been started. Tonic clonic convulsion had been controlled with intravenous diazepam infusion. $\mathrm{NaHCO}_{3}$ infusion $(2 \mathrm{mEq} / \mathrm{kg}$ dose in 20 minutes) had been started and the patient transported to our pediatric emergency department. 


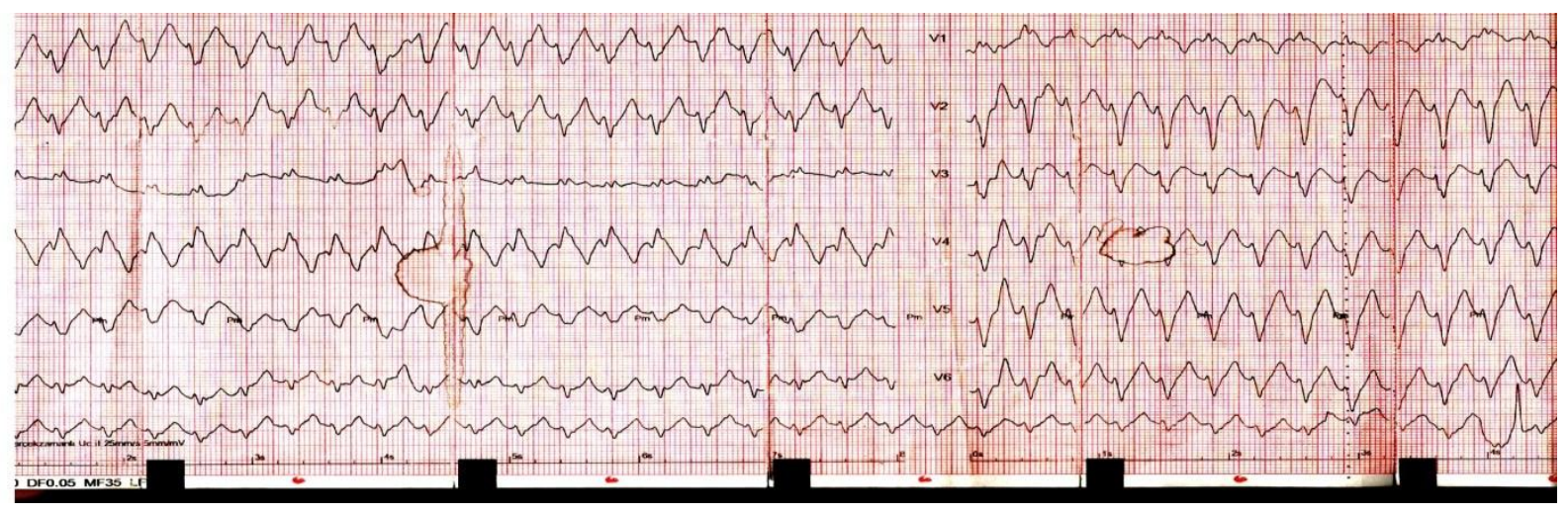

Fig. 1: The first electrocardiography that was evaluated as ventricular tachycardia (2nd hour of the event).

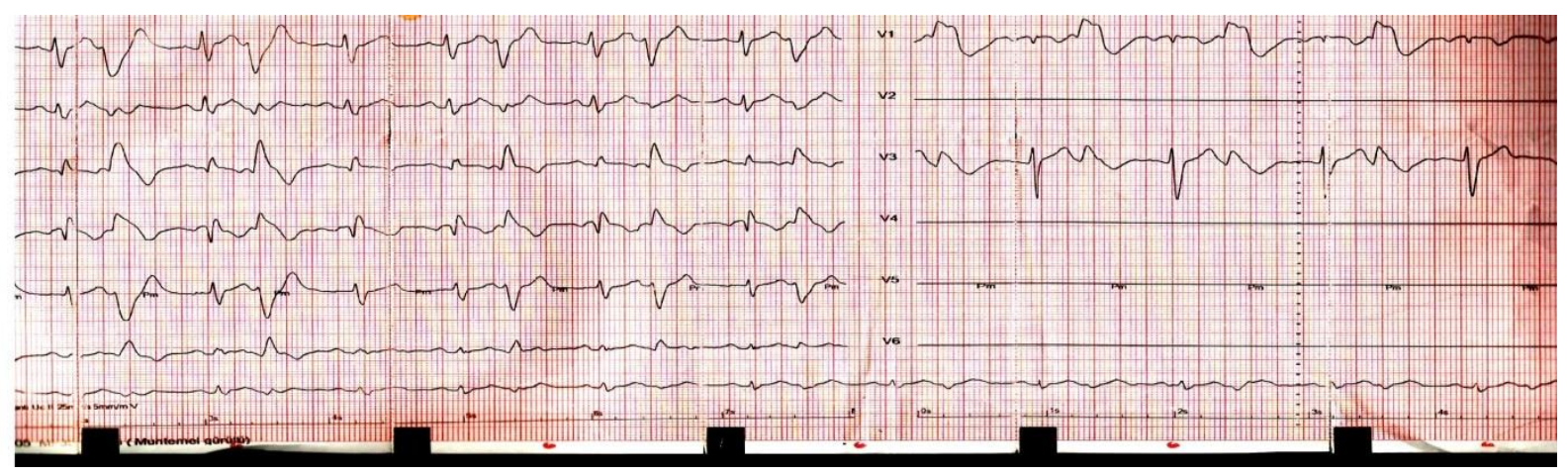

Fig. 2: Frequent ventricular premature contractions with sinus beats. Configuration of the premature contractions are not identical with the QRS morphology of the first electrocardiography.

The patient admitted to our emergency department at the $8^{\text {th }}$ hour of the event.

The patient was unconscious, the Glascow Coma Score (GCS) was 4 point, pupils were fixed dilated and pupillary light reflex was negative bilaterally. The patient had shallow breathing. Rhythm was irregular (Figure- 3), heart rate was 140/bpm and blood pressure was 75/41 mmHg. During the first examination generalized tonic clonic convulsion developed and was controlled by intravenous diazepam injection. She was intubated. Midazolam infusion was started. Intravenous fluid administration, containing $\mathrm{NaHCO}_{3}$ was started with a rate of 2000 $\mathrm{ml} / \mathrm{m}^{2}$. Dopamin infusion was started because of low blood pressure. 
The first electrocardiography (ECG) recordings (from the first admission center) revealed a wide QRS tachycardia (Figure- 1) with a right superior axis deviation (QRS duration was $0,15 \mathrm{~s}, \mathrm{QT}_{\mathrm{c}}$ was measured as $0.47-0.60 \mathrm{~s}$ ). "P" waves could not be identified. In another ECG (Figure- 2) frequent ventricular premature contractions with sinus beats were present. Configuration of the premature contractions was not identical with the QRS morphology of the first ECG. The first ECG recorded in our emergency room showed a wide QRS tachycardia (140 bpm) with a right bundle branch block and right inferior axis deviation and intermittent sinus beats after a short pause (Figure- 3). So, a definite differentiation between VT and a wide QRS sinus tachycardia as result of amitriptyline overdose $(4,6,7)$ could not be done. Lidocain infusion was continued.

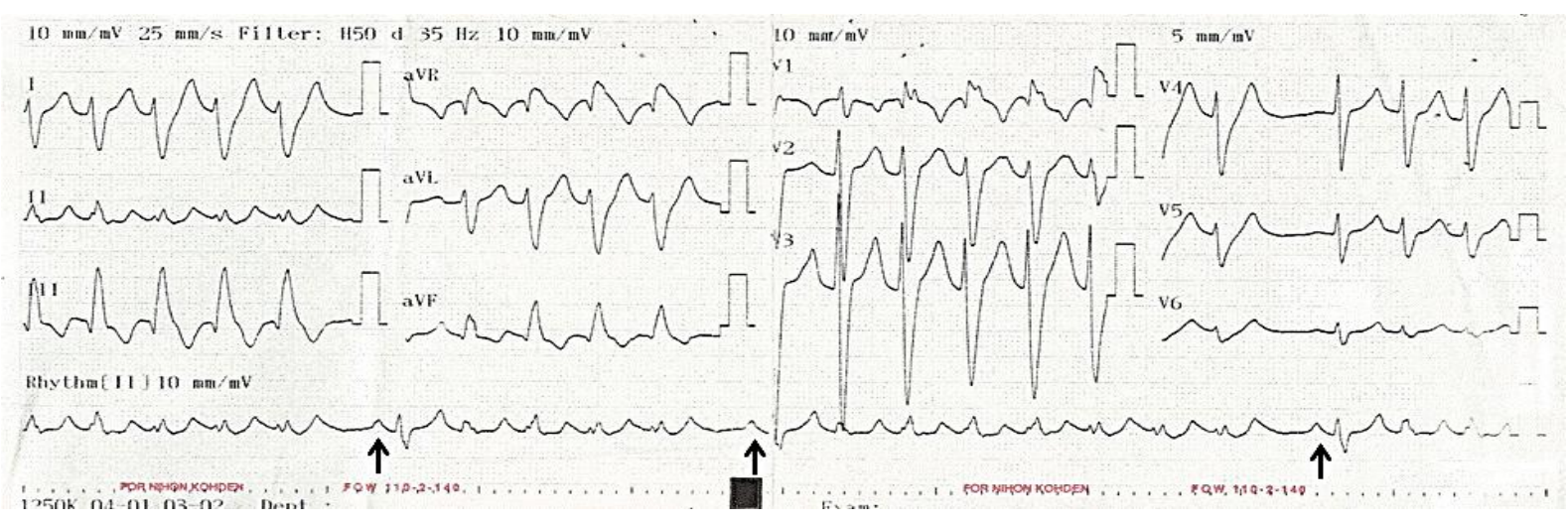

Fig. 3: The first electrocardiography recorded in our emergency room showed a wide QRS tachycardia $(140 \mathrm{bpm})$ with a right bundle branch block and right inferior axis deviation with intermittent sinus beats (arrow) after a short pause (8th hour of the event).

Two additional active charcoal was given with a 4-hour interval. Intravenous $20 \%$ lipid solution was administered (1.5 ml/kg bolus and $0.25 \mathrm{ml} / \mathrm{kg}$ in 30 minutes). Echocardiographic evaluation revealed a normal heart with normal left ventricular functions.

Complete blood count, liver function tests, renal functions and serum electrolyte levels $\left(\mathrm{Na}^{+}=138 \mathrm{mmol} / \mathrm{L}, \mathrm{Ca}=8.8 \mathrm{mg} / \mathrm{dL}, \mathrm{K}=3.5 \mathrm{mmol} / \mathrm{L}\right)$ were normal. Blood gase analysis showed respiratory acidosis $\left(\mathrm{pH}=7.26 \mathrm{pCO} 2=57.4 \mathrm{mmHg}, \mathrm{HCO}_{3}=25.1 \mathrm{mmol} / \mathrm{L}, \mathrm{Lac}=1.6 \mathrm{mmol} / \mathrm{L}\right.$, 
$\mathrm{BE}=-1)$ but returned to normal at the first hour of mechanical ventilation $(\mathrm{pH}=7.35$ $\left.\mathrm{pCO} 2=44.2 \mathrm{mmHg}, \mathrm{HCO}_{3}=24.1 \mathrm{mmol} / \mathrm{L}, \mathrm{Lac}=2.9 \mathrm{mmol} / \mathrm{L}, \mathrm{BE}=-0.7\right)$.

Despite the continuing $\mathrm{NaHCO}_{3}$ infusion, $\mathrm{pH}$ value was still not upper than 7.35 and the ECG findings persisted. So, selective plasma exchange was started at the $15^{\text {th }}$ hour of drug intake. During the procedure dobutamine was added to the treatment because of persisting low blood pressure. Selective plasma exchange was stopped at the $7^{\text {th }}$ hour of the procedure. Hemoglobin level decreased to $7.3 \mathrm{~g} / \mathrm{dl}$, so erythrocyte suspension was administered.

During this course, QRS morphology remained stable but the QRS duration become shorter and shorter (Figure- 4). In the ECG obtained at the $10^{\text {th }}$ hour of event "p" waves begin to appear, so lidocaine was ceased. At the $20^{\text {th }}$ hour of event the sinus rhythm with a right axis deviation settled. The PR interval was $0.14 \mathrm{~s}$ and the QRS duration was $0.08 \mathrm{~s}$ (Figure- 4). At the $27^{\text {th }}$ hour of event, right axis deviation was also corrected (Figure- 5). All these findings suggested that the ECG findings were the result of amitriptyline overdose, not VT. 


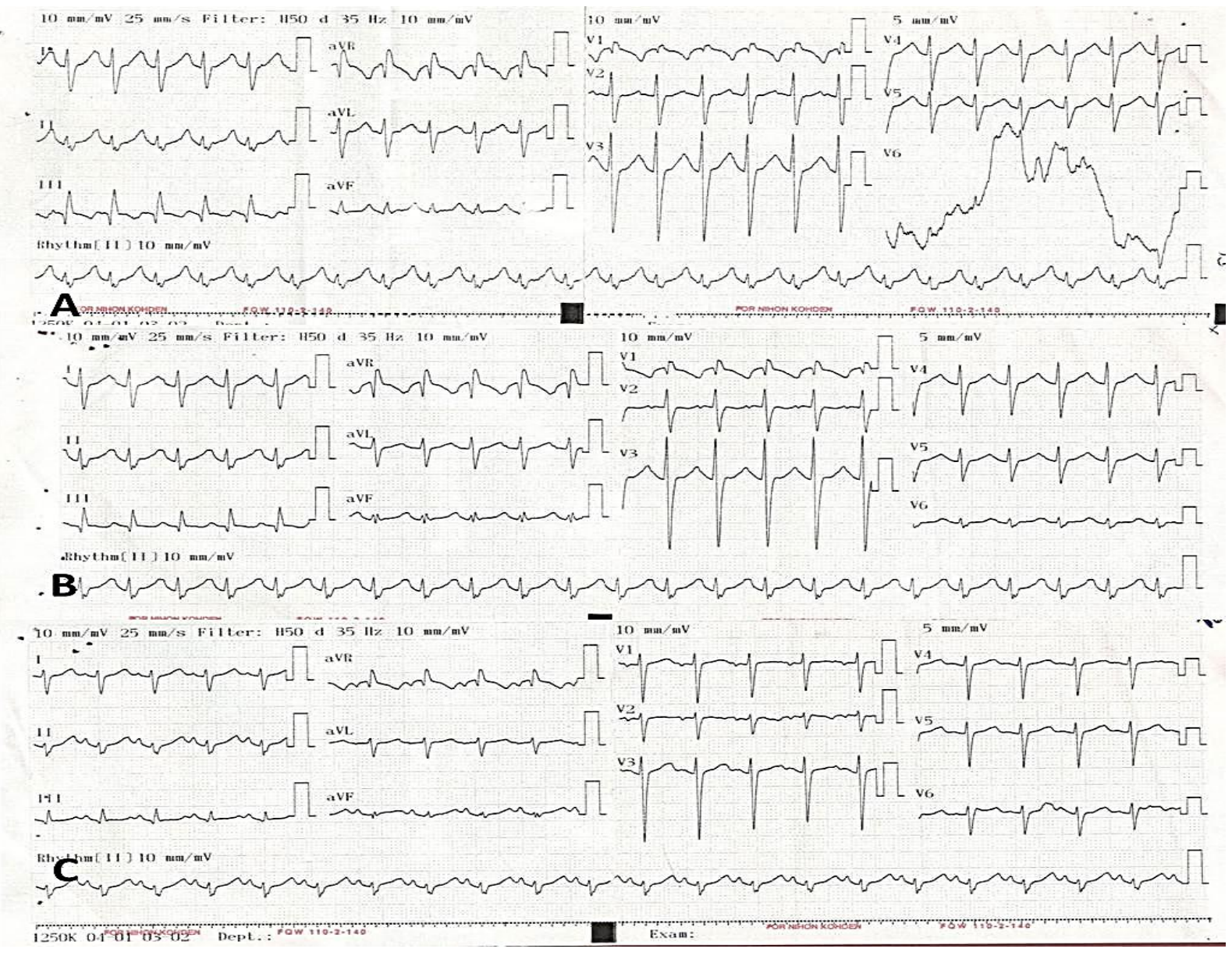

Fig. 4: The electrocardiography at the 9th (A), 10th (B) and 20th (C) hours of event. QRS morphology remained stable but the QRS duration become shorter and shorter. In the electrocardiography obtained at the 10th hour (B), "p" waves begin to appear, and it was apparent in the $20^{\text {th }}$ hour electrocardiography $(\mathrm{C})$.

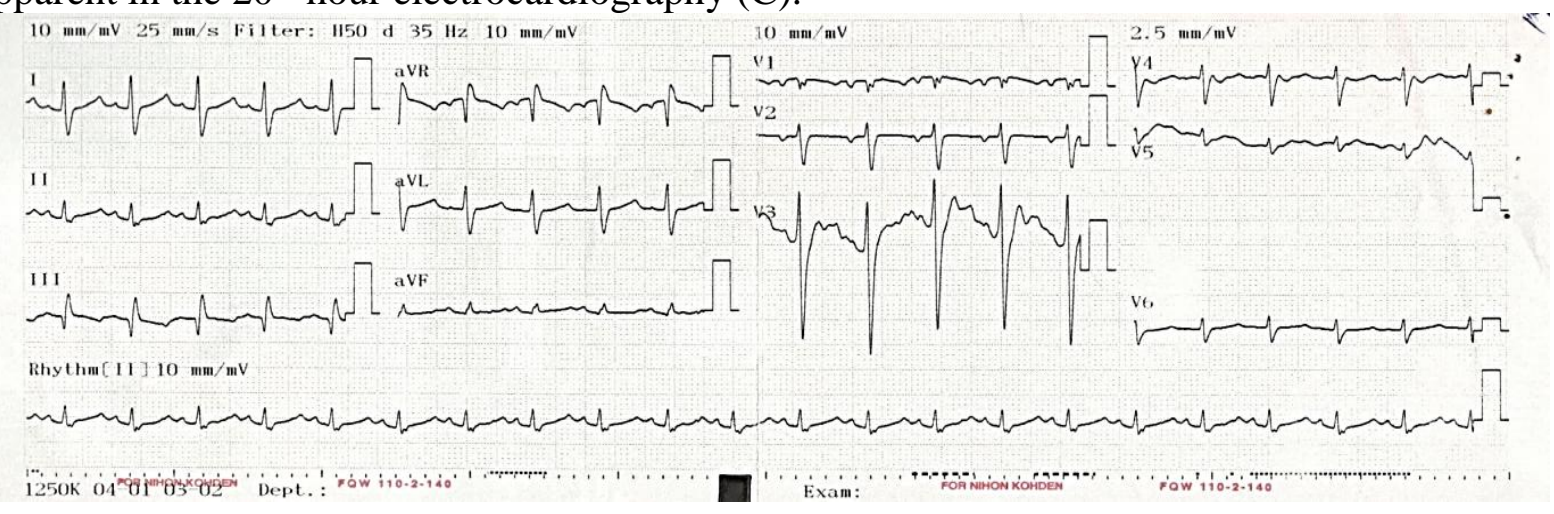

Fig. 5: At the 27th hour of event, right axis deviation was also corrected.

After completion of the plasma exchange, sedation was stopped and the patient was extubated successfully at approximately $32^{\text {th }}$ hour of event $(\mathrm{GCS}=14$ point $)$. Dopamin, dobutamine and NaHCO3 infusions were stopped. The patient went to normal room at the $34^{\text {th }}$ hour of event. 


\section{DISCUSSION}

Amitriptylin is one of the most common used antidepressants. Also the tricyclic antidepressants, especially the amitryptiline, are the most common used drugs in drug intoxication worldwide $(8,9)$. Acute results of amitriptyline intoxication had been well defined both in children and adults $(1,3,4,10)$.

Amitriptyline intoxication yields a variety of clinical signs and symptoms such as tachycardia, hypotension, anticholinergic findings such as dilated pupils, tachycardia, urinary retention, impaired consciousness ranging from lethargy to a comatose state, atrioventricular block, prolonged $\mathrm{QT}_{\mathrm{c}}$ interval or $\mathrm{QRS}$ duration, convulsions and dyspne due to respiratory depression, pulmonary insufficiency and occasionally adult respiratory distress syndrome (6, 7, 11, 12). Life threatening complications like convulsions, arrhythmia and respiratory depression are relatively more frequent among children than in adults (10).

Previous studies have shown that severe neurological and cardiovascular side effects arise from the blockage of voltage-dependent sodium channels (10). Although some studies suggest a relation between the serum drug level and the complications (10), some others indicate that severe toxic effects may occur with lower doses (2).

First-line treatment focuses on general measures as well as correction of electrolyte disorders and arrhythmia $(6,9)$. If the patient admits during the first 12 hours, gastric lavage should be performed and active charcoal should be administered. Respiration should be supported and hydration should be achieved. If conduction disturbance of arrhythmia is observed $\mathrm{NaHCO}_{3}$ should be given(5). For this purpose administration of hypertonic saline had also been proposed (13).

In case of amitrypitiline intoxication, phenytoin is no longer recommended for control of convulsions because of its limited efficacy and possible prodysrhythmic effects. Benzodiazepines are the most commonly prefered anti-convulsant drugs (14). As it is a lipid 
soluble drug intravenous lipid treatment has been applied in patients with amitriptyline intoxication $(15,16)$.

There is no known antidote against any of the tricyclic antidepressants. The American Society for Apheresis (ASFA) recommends plasmapheresis to support primary treatment in this type of drug poisoning, which does not respond to certain and traditional treatments (17). In patients with life threatening amitriptyline intoxication successful results had been reported with plasma exchange had been $(7,18-21)$. Recently one study reported successful result with extended high cut-off dialysis (9). In our case, we performed selective plasma exchange due to the persisting life threatening clinical condition despite all other treatment options.

Paksu et al (10) reported a relation between the serum sodium level and ECG findings and complications. However, in our patient despite the severe ECG findings neurological signs and depressed respiration the serum sodium level was normal.

The cardiac effects of tricyclic antidepressant poisoning are caused by a blockage of cardiac sodium channels in the His- Purkinje system and ventricular muscle. The ECG manifestations of slowed cardiac depolarization are prolongation of the QRS complex and an R-wave amplitude of $3 \mathrm{~mm}$ or higher in lead aVR (22). Some severe arrhythmias may also occur in these patients. Streanga et al (12) reported occurrence of ventricular premature beats, isolated, couplets and triplets, VT and torsade de pointes, and severe ventricular repolarization disturbances with diffuse subendocardial ischemia in 8 children with signs of amitriptyline intoxication.

Anticholinergic effects of the drug results in tachycardia (5). Slowing of intraventricular conduction, manifested by prolonged PR, QRS and QT intervals on the standard ECG are also well defined surface ECG findings of toxicity of tricyclic antidepressants (23). Wide QRS with prolonged PR and QT intervals results in disappearance "p" waves in the previous T waves. Because of this finding, the rhythm may be misdiagnosed as VT and cardioversion may be applied, especially in patients in whom rhythm is 
monitorised from one lead. So, in these patients 12-lead surface ECG should be evaluated and multiple leads should be monitorised for a long period carefully.

In our patient, the rhythm had been thought as VT (Figure- 1) in the first admitted center and lidocaine infusion had been started. In the second ECG (Figure- 2) there was frequent ventricular premature beats and the configuration of ventricular premature beats was not identical with the QRS morphology of the first ECG. Although we thought the first ECG as a result of amitryptiline toxicity, differentiation of VT could not be made. In the first ECG obtained in our clinic intermittent sinus beats were seen during a wide QRS tachycardia (Figure- 3). During follow-up heart rate gradually decreased, QRS duration shortened but QRS morphology remained similar (Figure- 4), and approximately in the ECG obtained at the $10^{\text {th }}$ and $20^{\text {th }}$ hours of event (Figure- 4) "p" waves became apparent. With appearance of " $p$ " waves VT was eliminated. These findings suggested us that the previous ECG findings were also result of amitriptyline effect not VT. At discharge, ECG was normal for the age of the patient (Figure- 5).

Amitriptyline intoxication may lead to severe neurological, respiratory and cardiac problems. ECG findings may not be differentiated from VT. In these patients survey may be well with aggressive treatment modalities. In addition to standard treatments, plasmapheresis should be kept in mind. 


\section{REFERENCES}

1. Caksen H, Akbayram S, Odabas D, Ozbek H, Erol M, Akgun C, Tuncer O, Yilmaz C. Acute amitriptyline intoxication: an analysis of 44 children. Human \& experimental toxicology 2006; 25: 107-10.

2. Grover CA, Flaherty B, Lung D, Pageler NM. Significant toxicity in a young female after low-dose tricyclic antidepressant ingestion. Pediatric emergency care. [Case Reports]. 2012; 28: 1066-9.

3. McFee RB, Caraccio TR, Mofenson HC. Selected tricyclic antidepressant ingestions involving children 6 years old or less. Academic emergency medicine : official journal of the Society for Academic Emergency Medicine 2001; 8: 139-44.

4. Olgun H, Yildirim ZK, Karacan M, Ceviz N. Clinical, electrocardiographic, and laboratory findings in children with amitriptyline intoxication. Pediatric emergency care. [Comparative Study]. 2009; 25: 170-3.

5. Webb AN, Joshi P. Toxidromes and Their Treatment. 2011; 1451-2.

6. Kerr GW, McGuffie AC, Wilkie S. Tricyclic antidepressant overdose: a review. Emergency medicine journal : EMJ. [Review]. 2001; 18: 236-41.

7. Sari I, Turkcuer I, Erurker T, Serinken M, Seyit M, Keskin A. Therapeutic plasma exchange in amitriptyline intoxication: case report and review of the literature. Transfusion and apheresis science : official journal of the World Apheresis Association : official journal of the European Society for Haemapheresis. [Case Reports Review]. 2011; 45: 183-5.

8. Mowry JB, Spyker DA, Cantilena LR, Jr., Bailey JE, Ford M. 2012 Annual Report of the American Association of Poison Control Centers' National Poison Data System (NPDS): 30th Annual Report. Clinical toxicology 2013; 5110: 949-1229. 
9. Schmidt JJ, Bertram A, Kuhn-Velten WN, Suhling H, Wiesner O, Schneider A, Kielstein JT. Treatment of amitriptyline intoxications by extended high cut-off dialysis. Clinical kidney journal 2015; 8: 796-9.

10. Paksu S, Duran L, Altuntas M, Zengin H, Salis O, Ozsevik SN, Albayrak H, Murat N, Guzel A, Paksu MS. Amitriptyline overdose in emergency department of university hospital: evaluation of 250 patients. Human \& experimental toxicology 2014; 33: 98090.

11. Lappa A, Castagna A, Imperiale C, Fenga M. Near fatal case of atrio-ventricular block induced by amitriptyline at therapeutic dose. Intensive care medicine. [Case Reports Letter]. 2000; 26: 1399.

12. Streanga V, Nistor N, Dimitriu AG, Cristogel F, Jitareanu C, Frasin M. [Cardiac arrhythmia in amitriptyline poisoning in children]. Revista medico-chirurgicala a Societatii de Medici si Naturalisti din Iasi 2005;109: 251-3.

13. Paksu MS, Zengin H, Ilkaya F, Paksu S, Guzel H, Ucar D et al.. Can empirical hypertonic saline or sodium bicarbonate treatment prevent the development of cardiotoxicity during serious amitriptyline poisoning? Experimental research. Cardiovascular journal of Africa 2015; 26: 134-9.

14. Citak A, Soysal DD, Ucsel R, Karabocuoglu M, Uzel N. Seizures associated with poisoning in children: tricyclic antidepressant intoxication. Pediatrics international : official journal of the Japan Pediatric Society 2006; 48: 582-5.

15. Eren Cevik S, Tasyurek T, Guneysel O. Intralipid emulsion treatment as an antidote in lipophilic drug intoxications. The American journal of emergency medicine. [Case Reports]. 2014; 32:1103-8.

16. Presley JD, Chyka PA. Intravenous lipid emulsion to reverse acute drug toxicity in pediatric patients. The Annals of pharmacotherapy. [Review]. 2013; 47: 735-43. 
17. Szczepiorkowski ZM, Winters JL, Bandarenko N, Kim HC, Linenberger ML, Marques MB. Guidelines on the use of therapeutic apheresis in clinical practice--evidencebased approach from the Apheresis Applications Committee of the American Society for Apheresis. Journal of clinical apheresis. [Practice Guideline]. 2010; 25: 83-177.

18. Bayrakci B, Unal S, Erkocoglu M, Gungor HY, Aksu S. Case reports of successful therapeutic plasma exchange in severe amitriptyline poisoning. Therapeutic apheresis and dialysis : official peer-reviewed journal of the International Society for Apheresis, the Japanese Society for Apheresis, the Japanese Society for Dialysis Therapy. [Case Reports]. 2007; 11: 452-4.

19. Belen B, Akman A, Yuksel N, Dilsiz G, Yenicesu I, Olgunturk R. A case report of amitriptyline poisoning successfully treated with the application of plasma exchange. Therapeutic apheresis and dialysis : official peer-reviewed journal of the International Society for Apheresis, the Japanese Society for Apheresis, the Japanese Society for Dialysis Therapy. [Case Reports]. 2009; 13: 147-9.

20. Karaci M, Ozcetin M, Dilsiz G, Guclu-Songur YG. Severe childhood amitriptyline intoxication and plasmapheresis: a case report. The Turkish journal of pediatrics. [Case Reports]. 2013; 55: 645-7.

21. Kolsal E, Tekin IO, Piskin E, Aydemir C, Akyuz M, Cabuk H, Eldes N, Numanoglu V. Treatment of severe amitriptyline intoxication with plasmapheresis. Journal of clinical apheresis. [Case Reports]. 2009; 24: 21-4.

22. Liebelt EL, Ulrich A, Francis PD, Woolf A. Serial electrocardiogram changes in acute tricyclic antidepressant overdoses. Critical care medicine. [Comparative Study]. 1997; 25: $1721-6$.

23. Pacher P, Kecskemeti V. Cardiovascular side effects of new antidepressants and antipsychotics: new drugs, old concerns? Current pharmaceutical design. [Research Support, Non-U.S. Gov't Review]. 2004; 10: 2463-75. 